\section{Experiências de abortos provocados em clínicas privadas no Nordeste brasileiro}

\author{
Personal experiences with induced abortions in \\ private clinics in Northeast Brazil
}

\section{Experiencias de abortos practicados en clínicas privadas del nordeste brasileño}

Paloma Silveira 1

Cecilia McCallum 1

Greice Menezes 1

\section{Resumo}

Baseado numa investigação qualitativa desenvolvida em 2012, o artigo analisa experiências de abortos provocados de pessoas de estratos sociais médios realizados em clínicas privadas. Foram narradas 34 histórias de gravidezes interrompidas em clínicas por 19 mulheres e cinco homens, residentes em duas capitais do Nordeste brasileiro. Uma análise temática revela que existem diferentes tipos de clinicas e de atendimento prestados pelos médicos. O artigo mostra que a realização de um aborto em uma clínica privada não é garantia de um atendimento humanizado e seguro. As narrativas fornecem descrições de diversas situações e práticas, desde aquelas com algumas falhas, como a falta de informações sobre os medicamentos, até outras com abusos graves, como procedimentos realizados sem anestesia. Assim, conclui-se que a ilegalidade da prática do aborto, no Brasil, permite que as clínicas funcionem sem qualquer tipo de regulação do Estado, não impedindo que as mulheres realizem abortos, mas as expondo a situações de total vulnerabilidade e de violação dos direitos humanos.

Aborto Induzido; Instituições de Assistência Ambulatorial;

Direitos Reprodutivos; Identidade de Gênero

\author{
1 Instituto de Saúde Coletiva, \\ Universidade Federal da \\ Correspondência \\ P. Silveira \\ Instituto de Saúde Coletiva, \\ Universidade Federal da \\ Bahia. \\ Rua Basílio da Gama s/n, \\ Salvador, BA 40110-040, \\ Brasil. \\ palomasilveira25@gmail.com
}




\section{Introdução}

As pesquisas científicas sobre o aborto no Brasil no campo da saúde pública têm sido realizadas, em sua maioria, com mulheres internadas em hospitais da rede pública de saúde, e desenvolvidas por pesquisadoras(es) que também são profissionais de saúde envolvidas(os) diretamente no seu cuidado. No contexto da ilegalidade do aborto, essa foi uma maneira encontrada para viabilizar a realização de estudos sobre o tema e enfrentar os desafios éticos 1,2 .

A concentração de pesquisas em serviços públicos de saúde apresenta alguns problemas. Primeiro, esses estudos terminam por analisar a situação exclusiva de mulheres com poucos recursos financeiros que se dirigirem aos hospitais públicos para finalizar o abortamento ou tratar das suas complicações. Isso leva ao desconhecimento das práticas abortivas e das circunstâncias pessoais, sociais e familiares de segmentos de mulheres que por diferentes meios conseguem interromper suas gravidezes de forma exitosa, e que não recorreram aos serviços públicos de saúde 1 . Também pode resultar em um viés, quando o leitor é levado a associar a prática do aborto às dificuldades econômicas e à desinformação das mulheres mais pobres e menos escolarizadas 3 .

A Pesquisa Nacional de Aborto (PNA) evidencia que o aborto é um evento frequente na vida reprodutiva das mulheres brasileiras de distintos estratos socioeconômicos ${ }^{4}$. Apesar de o aborto ser mais comum entre mulheres menos escolarizadas, é o desfecho mais frequente diante de uma gravidez não prevista entre aquelas de maior renda e instrução 5,6,7.

Contudo, ainda existem poucas investigações no Brasil sobre as experiências de abortos de mulheres de estratos sociais médios, permanecendo um grande desconhecimento quando a interrupção da gravidez é realizada em uma clínica privada 1 . O tema é ausente na produção científica, porém frequente nas páginas policiais. Entre os casos de mulheres presas por terem realizado aborto noticiados pela mídia, o da clínica de planejamento familiar em Campo Grande, no Mato Grosso do Sul, tornou-se emblemático.

Em 2007, a clínica foi fechada depois de denúncia de realização de abortos clandestinos. Na época, entre os anos de 2007 e 2008, muitos prontuários médicos foram apreendidos, quase mil mulheres foram indiciadas e, destas, 26 foram condenadas a cumprir penas alternativas 8,9. Anos mais tarde, no final de 2013, uma clínica privada que realizava abortos clandestinos no Rio de Janeiro também foi fechada, os médicos foram presos e a notícia foi veiculada na imprensa de forma espetacular: "Polícia Desarticula Maior Rede de Abortos do Rio" 10.

Identificou-se apenas uma investigação recente realizada em clínica privada no Brasil. Trata-se de um ensaio etnográfico da pesquisadora, ao acompanhar uma amiga no dia da realização do aborto 11. Sampaio 11 narra variadas situações vividas pelas mulheres na clínica. Em outros dois estudos, os autores analisam os itinerários abortivos de mulheres de estratos sociais médios, e de forma breve abordam a clínica privada. No primeiro, Diniz \& Medeiros 12 discutem os resultados da etapa qualitativa da PNA, focalizando o itinerário percorrido pelas mulheres para a realização da interrupção, os métodos utilizados e a rede de cuidados acionada. A clínica privada é apresentada apenas como um procedimento médico que as mulheres recorrem, cujo maior problema seria ter o recurso financeiro.

No segundo estudo, realizado por Heilborn et al. 13, os autores analisam os percursos de jovens mulheres e de seus parceiros, de distintas posições socioeconômicas, na busca de um aborto no Rio de Janeiro. Enfatizam também a disponibilidade financeira como condicionante para acessar a clínica privada. O itinerário dos jovens de camadas médias que utilizaram exclusivamente a clínica é descrito como mais direto, linear e seguro, relativamente àquele dos entrevistados de camadas populares, tido como mais tortuoso e inseguro.

Nesses dois trabalhos, o recurso à clínica privada é pouco explorado. Esta lacuna termina por reforçar o imaginário social de que a experiência das mulheres de camadas médias é homogênea e a realização de um aborto em clínica privada, por si só, é garantia de um bom atendimento e de uma assistência médica adequada.

O presente estudo ao analisar os relatos de abortos de mulheres e homens de estratos sociais médios, residentes em duas capitais do Nordeste brasileiro que realizaram abortos em clínicas privadas, problematiza e desmitifica a noção de homogeneidade das suas experiências. Ao ouvir as pessoas narrarem suas histórias, constatamos que há uma grande variedade de formas de vivenciar a interrupção da gravidez nesses espaços. Ainda ficou evidente que nas clínicas, a despeito do poder de compra, não há garantia de um tratamento seguro e humanizado.

\section{Metodologia}

Este trabalho faz parte de uma investigação qualitativa que teve como objetivo principal analisar as experiências de abortos de mulheres e homens pertencentes a estratos sociais médios 
do Nordeste brasileiro, focalizando a construção da decisão e o itinerário abortivo. Para esta pesquisa, partiu-se do pressuposto de que pessoas com acesso às clínicas privadas com atendimento médico muito provavelmente pertencem a estratos de maior renda familiar e escolaridade. Todavia, isso não exclui a possibilidade de que indivíduos pertencentes a estratos sociais médios não possam fazer uso de outros recursos/ procedimentos para interromper a gravidez, bem como a utilização concomitante de mais de um recurso. Assim, adicionalmente levamos em consideração a ocupação das pessoas e o bairro de moradia. Para classificar os bairros, além do conhecimento da pesquisadora, seguimos a percepção que os participantes da pesquisa têm destes.

No período de maio a dezembro de 2012 foram entrevistadas 20 mulheres e 7 homens com idades entre 24 e 49 anos, residentes na Grande Salvador e na Grande Recife e que tinham passado pela experiência do aborto provocado. Não foi fácil encontrar essas pessoas, sobretudo, os homens. A estratégia utilizada foi do tipo "bola de neve”. Após contatar e entrevistar algumas pessoas com experiência prévia de aborto provocado, com idades entre 18 e 49 anos, e que recorreram às clínicas privadas, estas sugeriam novas indicações. Os pesquisados indicaram amigas(os) com experiência de aborto e algumas entrevistadas recomendaram os próprios parceiros ou ex-parceiros para participarem da pesquisa.

À proporção que se obtinham as indicações, as pessoas eram contatadas para explicações sobre a pesquisa e agendamento das entrevistas. Utilizamos um roteiro de entrevista semiestruturada, um específico para as mulheres e outro para os homens. Após levantar alguns dados sociodemográficos, as questões buscavam focalizar cada história de aborto. Todas as entrevistas foram realizadas pela primeira autora deste artigo, em locais que garantiram segurança e privacidade das(os) participantes, acertados previamente com elas(es). As entrevistas foram também transcritas e submetidas à análise temática pela mesma pesquisadora 14 .

Não foi definido um limite temporal quanto à ocorrência do aborto, sendo que os eventos aconteceram nos últimos 10 anos, para a maior parte das mulheres e dos homens entrevistados. Embora algumas histórias datem de mais de 10 anos, consideramos improvável que tenham ocorrido problemas de rememoração, face à riqueza de detalhes fornecidos sobre o que foi vivido, indicando o quão marcantes foram estas experiências.

Neste artigo, analisamos as histórias de abortos realizadas em clínicas privadas, narradas por 19 mulheres e por 5 homens, incluindo dois casais. No caso dos casais, cada cônjuge foi entrevistado separadamente, primeiro a mulher e, em outro momento, o homem. Todos os nomes utilizados neste trabalho são fictícios.

Ao todo foram relatadas 55 histórias de gravidezes que ocorreram ao longo da vida das pessoas: 42 de mulheres, 11 de homens e duas dos casais; 38 gravidezes foram interrompidas e destas, 34 em clínicas privadas utilizando métodos de intervenção cirúrgica: aspiração manual intrauterina (AMIU), aspiração elétrica a vácuo (AEV) ou a curetagem. As 34 histórias de abortos em clínicas ocorreram em distintas épocas, sendo a maior parte quando as pessoas ainda eram jovens (18-25 anos), nas primeiras gravidezes e em relações afetivas/sexuais consolidadas. A maioria das interrupções foi realizada entre um e três meses de gestação, não existindo histórias de abortamentos tardios 15 .

A pesquisa foi aprovada pelo Comitê de Ética em Pesquisa do Instituto de Saúde Coletiva, Universidade Federal da Bahia, parecer no 029-12/ CEP-ISC.

\section{Resultados}

\section{A escolha da clínica "top" ou clínica "popular"}

Antes da escolha do método abortivo, nossos entrevistados buscaram informações sobre os distintos métodos para interromper a gravidez, os riscos implicados em cada procedimento e como acessá-los. Procuraram amigas e amigos com histórias de abortamento e familiares, principalmente aqueles com atitudes mais liberais frente ao aborto ou que eram profissionais de saúde. Algumas mulheres ainda informaram ter consultado amigas vinculadas aos movimentos feministas, que se mostraram informantes privilegiadas nesta busca.

$\mathrm{Na}$ maior parte dos relatos, a segurança e a eficácia foram tidos como os aspectos fundamentais para a escolha do método, e o procedimento realizado por médico em uma clínica privada foi apontado como aquele que mais preenchia estes requisitos. A noção de segurança mencionada por algumas mulheres e por alguns homens entrevistados esteve relacionada, sobretudo, à possibilidade de realizar o aborto em condições que não colocassem a vida da mulher em risco. Adicionalmente, as pessoas tinham uma expectativa de que, ao realizarem o aborto em clínica privada, estariam menos expostas a eventuais situações de constrangimento moral e de punições legais, 
pelo maior sigilo e privacidade que este tipo de local ofereceria.

O relato de Gustavo ao participar ativamente do aborto da parceira Gabriela é exemplar, ao sintetizar o conjunto de critérios utilizados na escolha da clínica. Analisando as informações sobre os métodos abortivos fornecidos por uma amiga de Gabriela vinculada ao movimento feminista, ambos preferiram a clínica privada: “ $A$ gente optou de fato pela clínica, pela boa assistência médica, pelo mais seguro de todas as formas, era mais seguro pra saúde dela, era mais seguro pra nossa segurança e moral, no sentido de não se expor e tal, e pra nossa segurança também do ponto de vista jurídico (...) e tínhamos certeza que ia dar certo" (único aborto de ambos, quando tinham 22 anos em 2010).

Os aspectos pontuados por Gustavo remetem a um modelo ideal de clínica: um local seguro, com boa assistência médica e com menos exposição a constrangimentos morais e maus-tratos. De forma contrária à percepção do senso comum de que existe apenas um tipo de clínica privada, identificamos duas categorias de serviços: a clínica "top" e a clínica "popular". Essas se diferenciam pela localização geográfica, pelos valores cobrados e pela infraestrutura.

Assim, as clínicas “tops” estão localizadas em bairros de estratos sociais médios ou altos e cobram valores elevados para realizar os abortos. Funcionam como clínicas de ginecologia e obstetrícia retratadas como lugares de "luxo", que têm equipamentos modernos, incluindo em alguns casos ultrassom. Nelas, vigora um tipo de código para se referir ao aborto, como relatou Clara: "Era uma clínica de luxo, top assim, esperei, era visivelmente uma clínica de ginecologia mesmo. Esperei, e ao entrar em contato com a recepcionista eu me identifiquei, disse o horário da minha consulta e ela me perguntou: é a primeira vez? Aí eu falei assim é a primeira vez, com doutor fulano de tal. Mas você pretende continuar sendo acompanhada por ele? Eu falei: não. Ela: ah tá. Aî ela pegou os meus dados, pegou meus dados não, só pegou o meu nome e pediu para eu aguardar" (único aborto, aos 24 anos em 2009).

Já as clínicas “populares” estão localizadas nos centros das cidades ou em bairros periféricos. Funcionam em locais descritos como mais "simples" e cobram valores mais acessíveis quando comparados aos das clínicas “tops”. Lá, não existem códigos de acesso, pois "as pessoas sabem que elas só funcionam para isso", como relatou Laura: "Esse marido da minha amiga procurou saber, ele tinha mais conhecimento, tinha mais experiência, aí ele conseguiu um lugar e uma de minhas colegas conseguiu uma clínica particular, top assim, lá no Z, ele conseguiu uma clínica clan- destina, mas assim popular (...). As pessoas sabem dessa clínica, que elas só funcionam para isso, ela é lá em $W$, no lugar $Y$, o médico falou quanto era, $e$ era bem mais barato. Não achei o lugar sujo, não era um lugar top, mas não era um lugar assim de sujeira, era bem simples" (duas gravidezes, um aborto aos 20/21 anos em 2000).

A grande maioria dos abortos relatados ocorreu em clínicas "tops” e apenas quatro em clínicas "populares”. Apesar de desejarem uma clínica "top", mas pelas dificuldades em arcar com os custos destes locais, essas mulheres foram obrigadas a recorrer a uma clínica "popular". Laura, em sua primeira gravidez, era ainda estudante e namorava um professor sem muitos recursos. Ambos avaliaram que o alto valor informado do procedimento na clínica "top" estava acima de suas possibilidades: "Aí eu primeiro fui nessa clínica top, quando ele [o médico] falou quanto era, eu fiz: me lenhei, porque era mil reais na época, tem o quê? 12 anos atrás. Mil reais para uma estudante, bancada pela mãe e pelo pai, o namorado professor, impossível. Eu saí de lá chorando, é impossivel, me lenhei (...). Aí fui nessa clínica popular que esse marido de minha amiga conseguiu".

O custo do aborto é o principal elemento que condiciona a escolha do método e também do tipo de clínica. Para as pessoas que detinham capital econômico, a escolha foi rápida. Para outras, no entanto, foi preciso esperar reunir o recurso necessário. Nas gravidezes que ocorreram sobretudo quando eram jovens, mulheres e homens, ainda sem renda própria, tiveram de acionar uma rede de relações sociais para ajudar na obtenção desse recurso. A importância do capital social e a capacidade de mobilizar essas redes não podem ser subestimadas. Esse capital pode ser medido não apenas pela extensão da rede, mas também pela identificação de quem participa e de suas posições de poder. Os agentes podem obter mais recursos se acionam pessoas poderosas, mesmo que inseridas em redes não muito extensas 16 .

As pessoas jovens recorreram a amigos e, em poucos casos, aos familiares para o pagamento do procedimento. Ane engravidou a primeira vez aos 22 anos, em 2009. Na época ela e o namorado eram estudantes, e conseguiram a quantia para pagar o aborto numa clínica “top” por meio de uma cotização entre seus amigos: "Na época não trabalhava, só estudava, e muito menos ele [namorado]. Eu não tinha como conseguir todo o dinheiro, porque eu não podia chegar em casa e dizer assim: ah meu pai eu preciso de mil e tantos reais pra eu poder abortar. Aí alguns amigos me ajudaram, meu e dele, cada um foi dando um pouco e conseguimos reunir o dinheiro necessário, 
1.500 reais na época" (duas gravidezes, dois abortos. O segundo em 2010, aos 23 anos).

As clínicas privadas funcionam com leis e regras próprias. Não há qualquer tipo de regulamentação sobre os valores ali cobrados, sendo estes bastante diferentes segundo o tipo de clínica. A idade gestacional da mulher também condiciona o preço do procedimento, sendo mais elevado quanto mais tardio for o tempo da gravidez, como contou Carol, que realizou dois abortos em 2008, aos 28 anos: "Eu paguei 2.000 reais na época em cada aborto. Esse foi o valor nas minhas duas gravidezes, a primeira foi com quase dois meses e a outra foi bem no início. Segundo o pessoal lá na clínica, o médico, o valor aumenta quando a gravidez é muito avançada e pode complicar também. Então, se eu fosse mais tarde ia pagar mais caro".

Mulheres e homens, cujas histórias de abortos ocorreram nas décadas de 1980 e 1990 não lembram os valores pagos. Entretanto, comparando-se os valores de procedimentos realizados em um mesmo ano ou em períodos próximos, observa-se que estes variaram entre clínicas do mesmo tipo e entre as cidades, mesmo com a informação de idades gestacionais diferentes. Apenas manteve-se a diferença entre as clínicas "tops" e as "populares", com as primeiras cobrando valores até três vezes mais altos do que as segundas, sobretudo em anos mais recentes. Tanto em Recife como em Salvador, um aborto em uma clínica "top" custava em torno de dois a três mil reais, entre 2010 e 2011.

Todas as pessoas entrevistadas mencionaram ter efetuado o pagamento em espécie. Em certas clínicas algumas mulheres informaram ter conseguido negociar o valor com o médico. A ilegalidade da prática do aborto no Brasil favorece a organização de um "mercado" clandestino que funciona de forma paralela, com autonomia absoluta dos médicos para determinar os valores cobrados, estando isentos de qualquer tipo de imposto ou regulação do Estado. Algumas entrevistadas, como Natália, enfatizaram esse aspecto: "E eu senti assim que era uma coisa tão corriqueira, o que passava na minha cabeça era dizer assim: nossa! Esse médico é muito rico, ele é milionário, porque se tem seis aqui nessa sala de espera, é 12 mil no dia, entendeu? Em dinheiro vivo, então assim ele ganha muita grana" (único aborto em 2011, aos 28 anos).

A maior parte das entrevistadas, independentemente do tipo de clínica, "top" ou "popular", mencionou que uma consulta inicial com o médico que realizaria o procedimento precedeu o momento do aborto. Nessa primeira consulta, o profissional conversou sobre a decisão pelo aborto e solicitou exames, principalmente o ultrassom, que algumas realizaram no próprio local, no caso das clínicas "tops", e a maior parte dos médicos, nas distintas clínicas, informou só realizar abortos até três meses de gestação.

Em alguns casos, as mulheres interromperam a gravidez no primeiro contato presencial. Foram, sobretudo, aquelas com histórias de mais de um aborto que, tendo adquirido um conhecimento prático sobre como interromper uma gravidez em uma clínica privada e, compreendido a sua forma de funcionamento, diante de um novo evento acessaram diretamente os locais onde haviam realizado os primeiros abortos, como disse Manuela: "Na primeira foi mais demorado, porque tive toda essa história de mapear o que a gente podia fazer, o que era mais seguro, de buscar referência (...). Então assim, foi um outro processo, o segundo a gente já sabia mais ou menos o caminho das pedras, então, foi mais tranquilo, já fui direto na clínica, com tudo certo e fiz no mesmo dia" (duas gravidezes, dois abortos: em 1996, aos 20 anos e em 2007, aos 31).

Para a maioria das mulheres o aborto não poderia ser realizado em qualquer dia. Essa escolha foi condicionada pela necessidade de compatibilizar o dia com a dinâmica das diferentes esferas de suas vidas como trabalho, família, responsabilidade sobre cuidados com os filhos etc., como relatou Paula em seu único aborto em 2009, aos 34 anos: "Eu disse a ele que eu queria uma sextafeira, pra me ficar sábado e domingo e eu ter como ir pra algum lugar e não ir diretamente pra casa, aí ele: não, tudo bem".

Assim, com o tempo organizado para o procedimento e a recuperação, o aborto pôde ser realizado e mantido como um tipo de segredo.

\section{O dia da interrupção}

No dia da interrupção, em que pese as diferenças das clínicas mencionadas, três momentos foram identificados: (1) a preparação do corpo; (2) a realização do procedimento de esvaziamento uterino; e (3) o repouso imediato após o procedimento ainda na clínica. Apesar de ser constituído por esses momentos, o processo foi rápido. A permanência na clínica no dia da interrupção foi de no máximo uma hora e meia.

No primeiro momento, de preparação do corpo, as mulheres, já acomodadas em uma sala específica da clínica, receberam alguns medicamentos. A maior parte delas não soube especificar o tipo de droga, por não lembrarem ou por não terem sido informadas pelos profissionais. Para algumas foi um anestésico, como relatou Laura em aborto numa clínica "popular": "Os comprimidos eu acho que eram anestésicos. Ela [técnica de enfermagem] me deu assim uns seis 
comprimidos e demorou um tempo assim, tipo 40 minutos, fiquei numa sala tipo de pré-parto, numa macazinha".

Já para outras, foi algo percebido como para dilatar o colo uterino, conforme informou Clara em uma clínica "top": "Aí tomei um anestésico, esperei algum tempo, pra o anestésico fazer efeito. Na verdade não, o remédio que eu tomei era para dilatar o colo, se eu não me engano".

Em alguns casos, essa preparação foi iniciada ainda em casa, com a utilização de medicamentos prescritos na primeira consulta, como ocorreu com Ane no seu primeiro aborto em uma clínica "top": "E de manhã assim normal em casa, como se eu não fosse fazer nada, me preparando pra de tarde, tomando o remédio que ele [médico] receitou [na consulta] para tomar antes".

Nesse primeiro momento, as mulheres, na maioria das vezes, relataram que foi permitida a presença de acompanhantes familiares, parceiros e, sobretudo, amigas/os. A rede de relações sociais foi mais uma vez acionada, sendo uma importante fonte de apoio emocional. Contudo, posteriormente, no segundo momento, da realização do procedimento de esvaziamento uterino, a maior parte dos acompanhantes, independentemente do sexo, teve de aguardar na "sala de espera”. Para os homens, particularmente, a ida à clínica representou um momento de limitação da atuação masculina no campo reprodutivo, como disse Iuri: "Eu também não pude entrar, fiquei só na sala de espera, eu queria ter entrado, afinal de contas, acho que essas coisas, se você tá junto, é preciso participar de todas as etapas, mas o fato é que o médico não permitiu" (três gravidezes da mesma parceira e dois abortos: em 1984, aos 19/20 anos e em 2005, aos 39).

Depois de um breve tempo, cerca de $30 \mathrm{mi}$ nutos, após os medicamentos fazerem efeito, as mulheres relataram terem sido encaminhadas para outra sala onde o procedimento foi realizado, com duração máxima de 40 minutos. Nesse segundo momento, diferentes experiências foram relatadas. Uma primeira distinção diz respeito ao método utilizado. Aquelas que recorreram às diferentes clínicas "tops" foram submetidas, predominantemente, à aspiração, tanto a AMIU como a AEV. As informações sobre o método foram fornecidas por distintos profissionais. Clara contou: "A recepcionista me explicou qual era o método, que era o AMIU, que era um método de sucção. Ela me explicou que eu ficaria em posição ginecológica, e que o médico iria introduzir um aparelho que sugaria o sangue, o endométrio tava revestido de sangue e sugaria (...) que não teria anestesia".

Já Gabriela obteve as informações sobre a AEV com o próprio médico: "Eu perguntei se seria
AMIU, mas ele falou que AMIU já estava ultrapassado, ele me falou isso, que era elétrica (...) e esse foi ligado numa maquininha, parecia um, você já viu aqueles negócios de encher bola? (...) Então, introduz e abre com o bico de pato o colo e ele faz aspiração".

Nos quatro casos de abortos realizados em clínicas "populares", entretanto, o procedimento foi exclusivamente a curetagem, como relatou Maria em seu segundo aborto:

Maria: "Ele usou aquele método que inclusive é mais arriscado, né? O risco de furar o útero e tal, como é o nome dele ...".

Paloma: "Curetagem?".

Maria: "Isso, curetagem" (quatro gravidezes, três abortos: 1992, aos 18 anos, 2001, aos 27 e em 2002, aos 28 anos).

Uma segunda distinção é relativa à percepção das mulheres sobre a assistência prestada pelos médicos. Algumas se sentiram bem atendidas e assistidas, independentemente do tipo de clínica, como Gabriela que ressalta a postura acolhedora do médico durante todo o procedimento na clínica "top": "Quando eu reclamava que tava incomodando alguma coisa, ele falou: é só mais um pouquinho, já vai passar e tal, não tem como evitar, não ficou me tratando mal. Foi realmente o procedimento, foi muito acolhedor durante todo o processo".

Além da postura do médico, as mulheres destacaram a presença de uma enfermeira ou técnica de enfermagem. Essas profissionais tanto auxiliaram o médico no procedimento quanto foram importantes fontes de apoio emocional, como podemos perceber no relato de Laura que realizou o aborto em uma clínica "popular": "Na hora não tinha como chamar ninguém, aí a técnica veio perguntou se eu tava bem e tal, me deu umas medicações (...). É, a moça também passava a mão na cabeça, alisava: você tá bem minha filha? Não, eu tô bem e ele [o médico] só vai perguntando: tá sentindo alguma coisa? Não. Eu estou bem (...) ele foi bem cuidadoso, desde o primeiro contato".

Na maior parte das histórias de abortos as mulheres avaliaram o atendimento como bom. Contudo, chama a atenção que os relatos de bons atendimentos foram, sobretudo, de entrevistadas que haviam obtido indicação das clínicas com pessoas conhecidas dos médicos.

Outras experiências foram consideradas ruins, contrariando as expectativas prévias das mulheres. A atenção qualificada como ruim foi mencionada, sobretudo, nas segundas experiências de aborto e ocorreram independentemente do tipo de clínica. Manuela, na mesma clínica "top" onde realizou o seu primeiro aborto, relatou como a assistência foi marcada pela 
impessoalidade do médico e mesmo por uma forma agressiva de realizar o procedimento: " $O$ médico foi super descuidado numa situação que você tá muito vulnerável, colocou o instrumento de forma mais agressiva. Doeu. Eu senti que o ato em si foi muito mais doloroso do que o primeiro, eu não sei se ele fez de propósito ou não, mas não teve a menor sensibilidade. Na segunda vez, não teve esse processo de perguntar nada, já foi logo fazendo e assim, eu me senti como objeto ali".

$\mathrm{O}$ relato de Maria sobre o seu segundo aborto, realizado em uma clínica "popular", é ainda mais chocante, muito distinto da experiência prévia numa clínica "top". Nesse segundo, sua curetagem foi realizada de forma violenta, sem anestesia: "O cuidado que tinha sido com o profissional anterior de botar os dois na sala, de conversar, de saber se era aquilo mesmo, até do método, foi tudo diferente (...) ele fez uma curetagem sem anestesia, quando eu entrei na sala ele me disse que a anestesia tinha acabado, e aí eu fiz, vai assim mesmo. Mas foi muito ruim, foi uma verdadeira tortura, eu não sei como eu sobrevivi àquilo".

O terceiro e último momento do dia da interrupção ocorreu logo após a intervenção. As mulheres foram encaminhadas para uma sala onde permaneceram para um breve repouso. Naquele momento, o médico realizou um exame final e prescreveu medicações, geralmente anti-inflamatórios e antibióticos. A maioria, independentemente do tipo de clínica, relatou ter recebido orientações relacionadas aos cuidados que deveriam adotar como repouso e abstinência sexual, além de recomendações de caráter geral como boa alimentação. Também foram alertadas que diante de quaisquer intercorrências deveriam entrar em contato com a clínica, sendo-lhes fornecido o contato pessoal do médico.

Houve agendamento de uma consulta de retorno, entre 10 e 15 dias após o procedimento, na maior parte dos casos realizados em clínicas “tops”, mas não nas clínicas "populares”. Nessa ocasião, os médicos verificaram eventuais problemas e poucas mulheres mencionaram uma orientação sobre a contracepção pós-aborto. Não houve relatos de complicações graves pósaborto e nenhuma mulher precisou de internação hospitalar. Entretanto, algumas, especialmente aquelas cujos atendimentos nas clínicas foram qualificados como ruins, mencionaram a persistência de sintomas que causaram desconfortos.

\section{Considerações finais}

Os relatos das mulheres e dos homens entrevistados de estratos sociais médios sobre as clínicas em duas cidades do Nordeste são diversos, contrariando o imaginário social de homogeneidade das experiências. Fica evidente que há nítidas diferenças entre as clínicas particulares, "tops" e "populares". A clínica "popular" é um tipo de clínica com atendimento realizado por médico, e não deve ser confundida com a "casa das aborteiras”, um espaço doméstico em que pessoas, profissionais de saúde ou não, auxiliam as mulheres a abortar utilizando uma variedade de recursos: sondas, injeção de líquidos, dentre outros 12 .

No Brasil, as mortes ocasionadas por complicações pós-aborto atingem predominantemente mulheres jovens, negras, de estratos sociais baixos e que residem em áreas urbanas periféricas 1,17. Apesar do procedimento realizado nas clínicas mencionadas ser mais eficaz e seguro, como discutido aqui, a falta de controle sobre a prática médica ocasionada pela ilegalidade do aborto coloca as mulheres de estratos médios em uma posição de absoluto desamparo. A criminalização do aborto, no Brasil, atinge as mulheres de distintos estratos sociais, sujeitando-as às mesmas forças históricas, culturais e sociais que lhes impõem, na clandestinidade, uma situação de vulnerabilidade e um sofrimento desnecessário. Desse modo, a criminalização pune todas as mulheres, ainda que em graus diferenciados.

As pessoas entrevistadas tinham expectativas de que pagar por um serviço privado, mesmo que clandestino, garantiria um bom atendimento. Entretanto, elas se depararam com uma diversidade de tipos de serviço. Diferentemente do atendimento em uma clínica clandestina para mulheres de camadas médias de uma cidade da América do Sul, estudado por Stickler et al. 18, cujas pacientes foram bem atendidas e assistidas, no nosso estudo o recurso a uma clínica particular "top" ou "popular" não garantiu um atendimento humanizado.

Assim, mesmo pagando caro, algumas entrevistadas foram mal assistidas pelos médicos. Ouvimos relatos de falta de informação sobre os procedimentos, tratamento "insensível” recebido do médico, manipulação agressiva do método por parte do profissional e o caso dramático do aborto realizado por curetagem sem anestesia. Dois outros estudos, um realizado no Brasil 11 e outro em Buenos Aires, Argentina 19, também enfatizam a situação de total vulnerabilidade das mulheres que recorrem às clínicas privadas, nesses contextos em que o aborto é criminalizado e condenado moralmente.

No caso do presente trabalho, parte das nossas entrevistadas, mesmo pertencendo a estratos sociais médios, relatou experiências que as aproximam daquelas mulheres de camadas 
populares, usuárias das maternidades públicas, em que diversos estudos constataram deficiências na atenção e desumanização do atendimento. Esses estudos mostram a existência de atitudes discriminatórias que são expressas em julgamentos pelos profissionais de saúde, falta de informações sobre os procedimentos e punições pelo fato de as mulheres terem abortado 20,21. Um inquérito com usuárias de 19 hospitais públicos de três capitais do Nordeste evidencia como a impessoalidade na atenção, a falta de informações e a ausência do planejamento reprodutivo pós-aborto desconsideram as necessidades concretas das mulheres e sua capacidade de tomar decisões nos campos da sexualidade $\mathrm{e}$ da reprodução 22.

Nos serviços privados as mulheres ficam à mercê dos profissionais, ainda que algumas entrevistadas mencionem ter encontrado "bons" profissionais. As mulheres que podem pagar por abortos, se têm sua saúde física mais preservada e percursos menos tortuosos quando comparados aos realizados pelas mulheres de camadas populares 12,13 , não alcançam sua cidadania plena nem têm seus direitos reprodutivos respeitados; apenas consomem um serviço que não coloca suas vidas em risco.

Os médicos na maior parte das clínicas não respeitaram a Norma Técnica de Atenção Humanizada ao Abortamento 23. Esse documento apresenta uma série de recomendações visando não só aos cuidados imediatos às mulheres, particularmente a contracepção pós-aborto, mas também à humanização da atenção, com uma postura profissional ética e de respeito aos direitos humanos das mulheres. Os relatos indicam que cada médico adotava uma conduta própria quanto ao acolhimento das mulheres, nem sempre com escuta adequada, orientação sobre os procedimentos que seriam realizados, nem fornecendo escolhas contraceptivas pós-abortamento. Entretanto, cabe ressaltar que alguns abortos foram realizados antes da publicação, em 2005, da primeira versão da Norma.

Desse modo, a distinção quanto à atenção recebida não esteve diretamente relacionada ao tipo de clínica, mas às singularidades de cada local e, particularmente, à postura do médico e de sua equipe. Tanto na Grande Salvador quanto na Grande Recife houve relatos de pessoas que foram bem assistidas e atendidas, mostrando uma tendência ao pessoalismo 24 . Os médicos bem avaliados foram, principalmente, aqueles que conheciam as pessoas que indicaram as clínicas às mulheres.

Apesar das ações e dos serviços de saúde serem considerados como de relevância pública pela constituição vigente e o setor privado estar sujeito ao controle e fiscalização do Estado 25, as clínicas privadas que realizam abortos operam clandestinamente, estando fora deste controle. Representam sim um submundo criado pela própria lei que criminaliza o aborto. A criminalização, assim, não impede as mulheres de realizar o aborto, mas favorece a existência de serviços que violam os direitos humanos já consagrados das mulheres 26 .

\section{Colaboradores}

P. Silveira realizou a pesquisa e elaborou o artigo. C. McCallum e G. Menezes orientaram a pesquisa e colaboraram na elaboração e revisão do artigo.

\section{Agradecimentos}

Ao CNPq e à Capes pela bolsa de estudos concedida à primeira autora do artigo. A Andrés Trotta pela tradução do resumo para o espanhol. 


\section{Referências}

1. Departamento de Ciência e Tecnologia, Secretaria de Ciência, Tecnologia e Insumos Estratégicos, Ministério da Saúde. Aborto e saúde pública no Brasil: 20 anos. Brasília: Ministério da Saúde; 2009. (Série B. Textos Básicos de Saúde).

2. Menezes G, Aquino EML. Pesquisa sobre o aborto no Brasil: avanços e desafios para o campo da saúde coletiva. Cad Saúde Pública 2009; 25 Suppl 2:S193-204.

3. Ramírez-Gálvez MC. Os impasses do corpo: ausências e preeminências de homens e mulheres no caso do aborto voluntário [Dissertação de Mestrado]. Campinas: Instituto de Filosofia e Ciências Humanas, Universidade Estadual de Campinas; 1999.

4. Diniz D, Medeiros M. Aborto no Brasil: uma pesquisa domiciliar com técnica de urna. Ciênc Saúde Coletiva 2010; 15 Suppl 1:959-66.

5. Hardy E, Rebello I, Faúndes A. Aborto entre alunas e funcionárias de uma universidade brasileira. Rev Saúde Pública 1993; 27:113-6.

6. Pirotta KCM, Schor N. Intenções reprodutivas e práticas de regulação da fecundidade entre universitários. Rev Saúde Pública 2004; 38:495-502.

7. Menezes G. Aborto e juventude: um estudo em três capitais brasileiras [Tese de Doutorado]. Salvador: Instituto de Saúde Coletiva, Universidade Federal da Bahia; 2006.

8. Tussi FP. Aborto vivido, aborto pensado: aborto punido? As (inter)faces entre as esferas pública e privada em casos de aborto no Brasil [Dissertação de Mestrado]. Porto Alegre: Instituto de Filosofia e Ciências Humanas, Universidade Federal do Rio Grande do Sul; 2010.

9. Galli B, Sydow E, Adesse L. Autonomia reprodutiva em questão: relatos de mulheres sobre aborto e estigma em Mato Grosso do Sul. Rio de Janeiro: Ipas Brasil; 2010.

10. Constancio T. Polícia desarticula maior rede de abortos do Rio. Estadão 2013; $13 \mathrm{dez}$

11. Sampaio CAM. Vendem-se criminosas: um ensaio etnográfico em uma clínica contra a lei. Revista Bagoas 2013; 9:245-65.

12. Diniz D, Medeiros M. Itinerários e métodos do aborto ilegal em cinco capitais brasileiras. Ciênc Saúde Coletiva 2012; 17:1671-81.

13. Heilborn ML, Cabral CS, Brandão ER, Faro L, Cordeiro F, Azize RL, et al. Itinerários abortivos em contextos de clandestinidade na Cidade do Rio de Janeiro - Brasil. Ciênc Saúde Coletiva 2012; 17:1699-708.
14. Gomes R. Análise e interpretação de dados de pes quisa qualitativa. In: Minayo MCS, organizadora. Pesquisa social: teoria, método e criatividade. Petrópolis: Editora Vozes; 2010. p. 79-108.

15. Department of Reproductive Health and Research, World Health Organization. Safe abortion: technical and policy guidance for health systems. 2nd Ed. Geneva: Whorld Health Organization; 2012.

16. Bourdieu P. A distinção: crítica social do julgamento. São Paulo: Edusp; 2008.

17. Ipas Brasil/Instituto de Medicina Social, Universidade do Estado do Rio de Janeiro. Magnitude do aborto no Brasil: uma análise dos resultados de pesquisa. Brasil, 2007. http://www.ccr.org.br/ uploads/eventos/mag_aborto.pdf (acessado em 25/Mai/2015).

18. Strickler J, Heimburger A, Rodríguez K. El aborto clandestino en América Latina: perfil de una clínica. Nota de investigación. Perspectivas Internacionales en Planificación Familiar 2001; N Esp:24-7.

19. Chaneton J, Vacarezza N. La intemperie y lo intempestivo: experiencias del aborto voluntario en el relato de mujeres y varones. Buenos Aires: Marea; 2011.

20. Bertolani GBM, Oliveira EM. Mulheres em situação de abortamento: estudo de caso. Saúde Soc 2010; 19:286-301

21. Carneiro MF, Iriart JAB, Menezes GMS. "Largada sozinha, mas tudo bem”: paradoxos da experiência de mulheres na hospitalização por abortamento provocado em Salvador, Bahia, Brasil. Interface Comun Saúde Educ 2013; 17:405-18.

22. Aquino EML, Menezes G; Barreto-de-Araújo TV, Alves MT, Alves SV, Almeida MCC, et al. Qualidade da atenção ao aborto no Sistema Único de Saúde do Nordeste brasileiro: o que dizem as mulheres? Ciênc Saúde Coletiva 2012; 17:1765-76.

23. Departamento de Ciência e Tecnologia, Secretaria de Ciência, Tecnologia e Insumos Estratégicos, Ministério da Saúde. Atenção humanizada ao abortamento: norma técnica. 2a Ed. Brasília: Ministério da Saúde; 2011. (Série A. Normas e Manuais Técnicos) (Série Direitos Sexuais e Direitos Reprodutivos, Caderno 4).

24. Damatta R. A casa e a rua: espaço, cidadania, mulher e morte no Brasil. Rio de Janeiro: Editora Rocco; 1997.

25. Silva LMV, Souza LEPF, Cerdeira AJP, Pinto CMF, Oliveira RSA. Algumas características do setor privado de saúde de Salvador, Bahia, Brasil. Cad Saúde Pública 1997; 13:701-9.

26. Ardaillon D. O lugar do íntimo na cidadania de corpo inteiro. Estudos Feministas 1997; 5:376-88. 


\section{Abstract}

Based on a qualitative study conducted in 2012, the article analyzes middle-class individuals' experiences with induced abortions performed in private clinics. Thirty-four stories of induced abortions were narrated by 19 women and five men living in two state capitals in Northeast Brazil. Thematic analysis revealed differences in types of clinics and care provided by the physicians. The article shows that abortion in private clinics fails to guarantee safe or humane care. The narratives furnish descriptions of diverse situations and practices, ranging from flaws such as lack of information on medicines to others involving severe abuses like procedures performed without anesthesia. The article concludes that criminalization of abortion in Brazil allows clinics to operate with no state regulation; it does not prevent women from having abortions, but exposes them to total vulnerability and violation of human rights.

Induced Abortion; Ambulatory Care Facilities; Reproductive Rights; Gender Identity

\section{Resumen}

En base a una investigación cualitativa, desarrollada en 2012, el artículo analiza experiencias abortivas practicadas en personas de estratos sociales medios, realizadas en clínicas privadas. 19 mujeres y cinco hombres residentes en dos capitales del nordeste brasileño narraron 34 historias de embarazo interrumpido en clínicas de estas zonas. El análisis temático revela que existen diferentes tipos de clínicas y de atención, donde ejercen su labor los médicos. El artículo muestra que la práctica de un aborto en una clínica no es garantía de una atención humanizada y segura. Las historias describen diversas situaciones y prácticas, desde aquellas con algunos fallos tales como la falta de información sobre los medicamentos, hasta otras con abusos graves como procedimientos abortivos realizados sin anestesia. Por ello, se concluye que la ilegalidad de la práctica del aborto en Brasil permite que las clínicas funcionen sin ningún tipo de regulación del Estado, lo que no impide que las mujeres realicen abortos, exponiéndolas a situaciones de total vulnerabilidad y violación de sus derechos humanos.

Aborto Inducido; Instituiciones de Atención Ambulatoria; Derechos Reproductivos; Identidad de Género
Recebido em 17/Jan/2015

Versão final reapresentada em 10/Jun/2015 Aprovado em 01/Jul/2015 